\title{
Discussion: The Network Manager as Therapist
}

\author{
Vidar Stevens \\ University of Antwerp, Belgium \\ E-mail: vidar.stevens@uantwerpen.be
}

Received: June 27, 2017 Accepted: July 21, 2017 Online published: August 7, 2017

doi:10.5296/jpag.v7i3.11658 URL: https://doi.org/10.5296/jpag.v7i3.11658

\begin{abstract}
Collaborative networks are by governments increasingly used as vehicles for fostering concerted and innovative policy solutions. Scholars have, however, noted that the extent to which collaborative networks can actually contribute to the development of concerted and innovative policy action depends on how they are managed. Within the network management literature, we know already various roles a manager can perform to bring about 'collaborative advantages' in collaborative networks. Yet, in this article, I would like to present another role - that of the network manager as therapist - which can help actors in collaborative networks to deal with their discomforts they experience when participating in network processes.
\end{abstract}

Keywords: actor behavior, network management, therapeutic skills, governance, collaboration.

\section{A New Network Management Role}

Network management has been a widely debated subject in the public management and governance literature. Network management is in this article understood as, "the endeavors and interventions of a central actor ('the network manager') to facilitate collaborative networks, by shaping the conditions under which these governance networks operate and involved actors interact with each other" (Voets, Verhoest \& Molenveld, 2015:983). In the last 25 years, we have, amongst other things, learned how network managers can spur dialogue in a collaborative network, translate between different experiences and perceptions of task of network members, or reformulate multi-actor conflicts into dilemmas which can be balanced and settled (Huxham \& Vangen, 2005; Milward \& Provan, 2006; Agranoff, 2006; Koppenjan \& Klijn, 2004).

In addition, various taxonomies of management roles and tasks have been developed by scholars to bring about a collaborative advantage in networks, like Ansell \& Gash's Facilitative Leadership Model (2012), the network management triangle of Gaus (Stevens \& Verhoest, 2016), the hands-on and hands-off management approaches of Sørensen \& Torfing 
(2012), or the four management roles and tasks of Agger \& Sørensen (2016). Agger \& Sørensen (2016), for example, argue that managers of collaborative networks must act as pilots, whips, communicators, and culture-makers to ensure the formulation and design of concerted and integrated policy actions for the wicked societal challenges of the $21^{\text {st }}$ century. In a similar vein, Agranoff \& McGuire (2001) suggest that network managers must activate network members to collaborate, frame discussions, mobilize individuals to make a commitment to the joint undertaking, and synthesize the network by creating the environment and enhancing the conditions for favorable, productive interactions among network participants.

In my doctoral research, however, I encountered several network management strategies which I could neither connect to existing taxonomies of network management tasks and roles nor to earlier findings of network studies. Hence, in this article, I would like to share my observation that a network manager can act as a therapist, by taking individual network members aside and look with them for ways to cope with their personal dilemmas and discomforts they experience when participating in network processes.

\section{Behavioral Discomforts}

This observation follows from my doctoral study. In my doctoral study, I specifically focussed on how collaboration can spur the development of new, creative and concerted policy solutions, and what role management plays in these collaborative innovation processes. Often, governments move from the assumption that creative and innovative policy solutions emerge if more actors and thus more knowledge, resources, and experiences are included in the decision-making processes. I claimed, however, that the extent to which collaborations can actually contribute to the development of creative policy solutions for cross-cutting issues (like immigration, global warming, or spatial planning issues) depends on the way in which they are managed. Actors in collaborations may hold different problem perceptions, may be reluctant to collaborate, or may paralyze the decision-making process for strategic reasons. Therefore, management is necessary to get participants of collaborations moving in the same direction.

The collaborative networks I studied were, in every sense, collaborative connections between network members. The collaborative networks were all deliberately established with the purpose of formulating innovative, shared and overlapping policy objectives and solutions. The network members themselves were representatives, or what Williams (2002) has called 'boundary spanners', of their departmental organizations. Consequently, from the case studies it turned out that the network members' behaviors were mainly influenced by three particular factors: (1) the expectations and instructions from a network members' political or senior administrative leader; (2) the relationships, connections and behaviors of other network members in the collaborative network; and (3) the network member's personal beliefs, opinions and attitudes. In most instances, the network members determined on the basis of these three factors their behavior in the collaborative networks, or at least, they kept these factors in mind when engaging with their network peers.

In the interviews, many of my respondents, however, indicated they struggled with choosing 
an 'appropriate' way of behaving in the collaborative networks. The respondents had different interpretations of the term 'appropriate behavior', though generally, this entailed they had difficulty in behaving in such a way that their organizational interests were voiced in the network, without upsetting too many network alters or showing forms of actor behavior that went against their human nature. A shy respondent, for example, states that she felt very uncomfortable to play the decision-making game very roughly, but that there was no other way to secure her organizational interests, since "all other representatives acted as lions to protect their organizational territory." Another respondent denotes that he got the instructions to just go to the network meetings without making too many organizational commitments. Yet, he was of the opinion that his organization could benefit from working more closely with other departments on issues of coastal protection and preservation. As a result, he felt as if he was in a constant balancing act between what he believed was the right thing to do and what his senior administrative leaders expected him to do.

\section{A Therapeutic Management Approach}

In the collaborative networks I studied, the network managers utilized various network management strategies to accommodate the participation of network members. For most of these network management strategies, I was able to generalize and relate them to existing findings of network studies or taxonomies of network management roles and tasks.

One network manager, for example, tried to develop a shared language between network members by drafting a glossary of new words and definitions at the end of each meeting. The network manager noticed that during the discussions certain words seemed normal for some participants, while they were jargon for others. The network manager believed that the glossary could serve as a road map to further develop new concepts and program theories that better fit and defined the intertwined nature of spatial planning issues. This network management example aligns with one of the management tasks of the management role pilot of the taxonomy of Agger and Sørensen (2016), as they suggest that a network manager exercising the management role of communicator must, among other things, translate between the different views of stakeholders to spur dialogue in the collaborative network."

However, with regard to a specific cluster of network management strategies, I was unable to link them to existing findings or observations in the network management literature. These were particular one-on-one conversations the network managers in several of my case studies had with individual network members outside the general meetings to better understand their behavioral discomforts, and to discuss ways that would help the individuals to feel more comfortable in the dialogues and discussions in the network.

The aims, durations, and frequencies of these one-on-one conversations differed for the network members. Moreover, the focus of these conversations was not so much on how the network manager could better support the individual, but more on how the individual network member, through small cognitive or behavioral changes, would become more at ease with its role, tasks and behavior in the network setting. The network manager thus acted as a kind of 'therapist', and the network members were the 'patients' who, through discussing their personal problems with the network manager, hoped to become more comfortable in 
participating in the collaborative network.

\section{The Manager and the Inner-worlds of Network Members}

I believe there are two interrelated reasons why it was difficult to generalize these 'therapeutic' network interventions to earlier findings in the broader network management literature. First of all, when reading public management and governance studies it often seems as if scholars have the tendency to merely analyse the management of what Agranoff and McGuire (2001) call the 'groupware' of networks (i.e. group-based development processes and the search for collective results). There is relatively limited focus on the personal, or even emotional, state of network members participating in collaborations. Second, when scholars do discuss strategies directed at managing individuals in network settings, they mainly focus on how strategic or opportunistic actor behavior can be reduced. See, for example, the suggested management strategies of Koppenjan and Klijn (2004) targeted at reducing strategic uncertainty in collaborative networks. Such a view on managing individuals does not start from the intention to nurture the behavioral discomforts network members experience, but rather aims to make network members act according to a predetermined and normative image of the network manager about how individuals should behave in network settings.

To this end, for future research I encourage scholars to study in greater detail the inner-worlds (i.e. ideas, emotions, imaginations, and self-imposed rules) of network members during network processes, and to analyse empirically how network managers try to connect to these inner-worlds in their managing activities. This will enrich our understanding of what cognitively hinders network members in their boundary spanning activities, and how through conversation and guidance a network manager can better accommodate network members' participation in collaborations.

This suggestion for future research has similarities with the call of Grimmelikhuijsen, Jilke, Olsen \& Tummers (2017) to make more use of theories and methods of psychology to confirm, add nuance to, or extend classical public administration theories. They even argue that Behavioral Public Administration must become a sub-discipline in the Public Administration literature. Hence, I hope that the discussed observation of 'the network-manager as therapist' can add to these scholarly developments and can become a useful focal lens to supplement existing typologies of network management roles. This would, in turn, allow scholars to examine in greater detail neglected terrains or dynamics in network processes, like the network manager's interventions in unofficial circumstances with individual network members to manage their behavioral discomforts.

\section{References}

Agger, A., \& Sørensen, E. (2016). Managing Collaborative Innovation in Public Bureaucracies. Planning Theory. https://doi.org/10.1177/1473095216672500.

Agranoff, R. (2006). Inside Collaborative Networks: Ten Lessons for Public Managers. Public Administration Review, 66 (special issue), 56-65. https://doi.org/10.1111/j.1540-6210.2006.00666.x 
Agranoff, R., \& McGuire, M. (2001). Big Questions in Public Network Management Research. Journal of Public Administration Research and Theory, 11(3), 295-326. https://doi.org/10.1093/oxfordjournals.jpart.a003504

Ansell, C., \& Gash, A. (2012). Stewards, mediators and catalysts: Toward a Model of Collaborative Leadership. Innovation Journal: The Public Sector Innovation Journal, 17(1), $1-21$.

Grimmelikhuijsen, S., Jilke, S., Olsen, A. L., \& Tummers, L. (2017). Behaviorial Public Administration : Combinging Insights from Public Administration and Psychology. Public Administration Review, 77(1), 45-56. https://doi.org/10.1111/puar.12609

Huxman, C., \&Vangen, S. (2005). Managing to Collaborate; The Theory and Practice of Collaborative Advantages. London: Routledge.

Klijn, E. H., \& Koppenjan, J. (2004). Managing Uncertainties in Networks. New York: Routledge.

Milward, H. B., \& Provan, K. G. (2006). A Manager's Guide to Choosing and Using Collaborative Networks. Retrieved from the IBM Center for the Business of Government website: http://www.srpc.ca/ess2016/summit/Reference_9-Milner.pdf.

Sørensen, E., \& Torfing, J. (2012). Enhancing collaborative innovation in the public sector. Administration and Society, 43(8), 842-868. https://doi.org/10.1177/0095399711418768

Stevens, V., \& Verhoest, K. (2016a). How to Metagovern Collaborative Networks for the Promotion of Policy Innovations in a Dualistic Federal System?. The Innovation Journal: The Public Sector Innovation Journal, 21(2), 1-26.

Voets, J., Verhoest, K., \& Molenveld, A. (2015). Coordinating for Integrated Youth Care: The need for smart metagovernance. Public Management Review, 17(7), 1-21. https://doi.org/10.1080/14719037.2015.1029347

\section{Copyright Disclaimer}

Copyright for this article is retained by the author(s), with first publication rights granted to the journal.

This is an open-access article distributed under the terms and conditions of the Creative Commons Attribution license (http://creativecommons.org/licenses/by/4.0/). 